\title{
A socioeconomic analysis of intraoperative neurophysiological monitoring during spine surgery: national use, regional variation, and patient outcomes
}

\author{
Whitney Sheen James, M.D., M.H.S., ${ }^{1}$ Anand I. Rughani, M.D., ${ }^{2}$ \\ and Travis M. Dumont, M.D. ${ }^{1}$ \\ ${ }^{1}$ Division of Neurosurgery, University of Arizona, Tucson, Arizona; and ${ }^{2}$ Neuroscience Institute, Maine \\ Medical Center, Portland, Maine
}

Object. In the United States in recent years, a dramatic increase in the use of intraoperative neurophysiological monitoring (IONM) during spine surgeries has been suspected. Myriad reasons have been proposed, but no clear evidence confirming this trend has been available. In this study, the authors investigated the use of IONM during spine surgery, identified patterns of geographic variation, and analyzed the value of IONM for spine surgery cases.

Methods. In this retrospective analysis, the Nationwide Inpatient Sample was queried for all spine surgeries performed during 2007-2011. Use of IONM (International Classification of Diseases, Ninth Revision, code 00.94) was compared over time and between geographic regions, and its effect on patient independence at discharge and iatrogenic nerve injury was assessed.

Results. A total of 443,194 spine procedures were identified, of which $85 \%$ were elective and $15 \%$ were not elective. Use of IONM was recorded for 31,680 cases and increased each calendar year from 1\% of all cases in 2007 to $12 \%$ of all cases in 2011. Regional use of IONM ranged widely, from $8 \%$ of cases in the Northeast to $21 \%$ of cases in the West in 2011. Iatrogenic nerve and spinal cord injury were rare; they occurred in less than $1 \%$ of patients and did not significantly decrease when IONM was used.

Conclusions. As costs of spine surgeries continue to rise, it becomes necessary to examine and justify use of different medical technologies, including IONM, during spine surgery.

(http://thejns.org/doi/abs/10.3171/2014.8.FOCUS14449)

KeY Words • socioeconomics

\author{
neurophysiological monitoring •
}

\section{spine surgery}

A S costs of modern health care rise, it is prudent to frequently examine the use of different medical technologies and justify the rationales for their use. We examined use of intraoperative neurophysiological monitoring (IONM) during spine surgery, which commonly includes measuring and monitoring somatosensory evoked potentials, motor evoked potentials, electromyographic recordings, or any combination, ${ }^{5,12}$ during spine surgery.

Since the early 2000s, use of IONM for spine surgery is believed to have increased in almost every region of the country. Anecdotal evidence suggests that its use extends beyond cases such as scoliosis surgery and intrinsic spinal cord tumor surgery to now include relatively low-risk surgeries such as simple discectomy and anterior cervical discectomy and fusion. We investigated the use of IONM during spine surgery and patterns of its use in the United States.

\footnotetext{
Abbreviations used in this paper: ICD-9 = International Classification of Diseases, Ninth Revision; IONM = intraoperative neurophysiological monitoring; NIS = Nationwide Inpatient Sample.
}

\begin{abstract}
Methods
The Nationwide Inpatient Sample (NIS) was obtained from the Agency for Healthcare Research and Quality for the years 2007 (the 1st year of the International Classification of Diseases, Ninth Revision, [ICD-9] code for IONM) to 2011 (the most recent year with available data). Allowing for collection of up to 24 diagnoses in addition to a patient's primary diagnosis, this database includes roughly 8 million annual entries. It is designed to produce a representative sample of approximately $20 \%$ of all annual hospital inpatient admissions in the United States. For the most recent years available, 44 states (representing $95 \%$ of the US population) contributed to the NIS. The NIS stratifies data from hospital-based factors such as hospital size, location, teaching affiliation, and not-forprofit versus for-profit designation. Individual clinical records are generated by data abstraction. For the purposes of this study, individual cases were isolated on the basis of ICD-9 codes for common spine disorders (Table 1) and common spine surgery procedures (Table 2).

Each case was queried for use of IONM (ICD-9 code 00.94), and an estimate of premorbid condition was deter-
\end{abstract}


TABLE 1: Common spinal disorders queried from the NIS database, 2007-2011

\begin{tabular}{lc}
\hline \multicolumn{1}{c}{ Diagnosis } & ICD-9 Code* \\
\hline malignant neoplasm of spinal cord & 192.2 \\
malignant neoplasm of spinal meninges & 192.3 \\
benign neoplasm of spinal cord & 225.3 \\
benign neoplasm of spinal meninges & 225.4 \\
intervertebral disc disorders & $722 . x$ \\
acquired spondylolisthesis & 738.4 \\
fracture of vertebral column w/o mention of spinal & $805 . x$ \\
$\quad$ cord injury & $806 . x$ \\
\hline
\end{tabular}

* $x$ designates $0-9$, codes based on diagnosis level/location.

mined according to the Elixhauser comorbidity score ${ }^{2}$ (an ICD-9 diagnosis-based system that considers a patient's comorbid state, which could be associated with prolonged hospitalization). The score is based on summation of the presence or absence of diagnostic codes listed for up to 30 disease groups; scores range from 0 to 3 . Use of IONM was compared between calendar years across primary diagnoses, surgical levels operated on, US geographic regions, hospital locations (urban or rural), and hospital teaching status. Nerve injury (ICD-9 957.9) and spinal cord injury (ICD-9 252.0-252.9) for elective procedures were considered new diagnoses, and we compared their incidence with or without use of IONM.

For analysis of discharge disposition, we compared patient independence at discharge (defined as routine or with in-home services) with discharge to a facility other than home. Use of IONM was reported as a percentage of total queried cases per year. Statistical comparison between groups was performed by using the Fisher exact and analysis of variance tests in SAS 9.2 (SAS Institute Incorporated). For all statistical comparisons, an alpha level of 0.05 was used to determine statistical significance.

\section{Results}

We identified 443,194 spine procedures, of which $85 \%$ were elective and $15 \%$ were not elective. Use of IONM was reported for $31,680(7.15 \%)$ of these cases. Use of IONM increased each calendar year, from a low of $1 \%$ of all spine surgery cases in 2007 to a high of $12 \%$ of all spine surgery cases in 2011. IONM use increased regardless of diagnosis or surgical location (Table 3). Even

TABLE 2: Common spine surgery procedures queried from NIS database, 2007-2011

\begin{tabular}{lc}
\hline \multicolumn{1}{c}{ Procedure } & ICD-9 Code $^{*}$ \\
\hline laminectomy or laminotomy & 3.09 \\
spinal fusion & $81.0 \mathrm{x}$ \\
laminectomy w/ excision of intervertebral disc & 80.51 \\
\hline
\end{tabular}

* $x$ designates $0-9$, codes based on fusion level and approach.
TABLE 3: Yearly percentage use of IONM in the United States, by diagnosis and surgical level

\begin{tabular}{lrrrrr}
\hline \multirow{2}{*}{ Variable } & \multicolumn{5}{c}{ ONM Use (\%) } \\
\cline { 2 - 6 } & 2007 & 2008 & 2009 & 2010 & 2011 \\
\hline diagnosis & & & & & \\
$\quad$ fracture & 0.6 & 6.5 & 7.7 & 11.5 & 12.0 \\
disc degeneration & 0.8 & 5.6 & 8.7 & 13.0 & 14.8 \\
disc displacement & 0.5 & 2.9 & 6.3 & 7.4 & 8.9 \\
myelopathy & 0.5 & 7.0 & 8.6 & 12.0 & 14.1 \\
tumor of meninges & 3.6 & 16.9 & 30.3 & 35.6 & 35.7 \\
tumor of spinal cord & 5.0 & 24.2 & 33.6 & 38.1 & 45.9 \\
location & & & & & \\
cervical & 0.6 & 4.6 & 8.0 & 8.7 & 10.5 \\
thoracic & 0.7 & 6.1 & 7.6 & 11.6 & 11.6 \\
thoracolumbar & 0.5 & 3.4 & 6.7 & 9.3 & 10.9 \\
lumbar & 0.6 & 7.2 & 7.5 & 11.8 & 12.6 \\
\hline
\end{tabular}

discectomy for "disc displacement" showed a steady rise in use of IONM from $2.9 \%$ in 2008 to $8.9 \%$ in 2011 .

IONM use between hospital geographic regions, relative population (urban/rural), and teaching status was not uniform. Regional variations were most pronounced in 2011 (the most recent year studied), when the regional low was $8 \%$ of cases in the Northeast and the regional high was $21 \%$ of cases in the West (Fig. 1). With the exception of the Northeast, use of IONM during spine surgery increased in all other US regions from 2007 to 2011 (Fig. 1). Use of IONM during spine surgeries was more common in hospitals in urban (7\%) than in rural settings (4\%) and in nonteaching (8\%) than in teaching $(6 \%)$ hospitals.

For elective and nonelective spine surgery patients, the likelihood of independence at discharge was diminished for patients in whom IONM was used (OR 0.842, $\mathrm{p}<0.001$, and OR 0.846, $p<0.001$, respectively). When individual types of spine surgery performed were compared and admission type and comorbidities were controlled for, among patients without myelopathy who underwent anterior cervical discectomy and fusion surgery, independence at discharge did not differ among those in whom IONM was or was not used $(98 \%$ vs $98 \%$, respectively, $p=1.000$ ). The only surgery for which IONM was associated with improved independence at discharge was posterior thoracic fusion (OR 1.102, $\mathrm{p}=0.05$ ). No statistically significant benefit for use of IONM during other spine surgeries or for patients with other diagnoses was detected (Table 4).

Among the patients sampled, iatrogenic nerve injury and spinal cord injury during elective procedures were extraordinarily rare. Of the 443,194 spine surgery cases queried, only 20 iatrogenic nerve injuries were reported; incidence $(\mathrm{p}=1.000)$ did not differ significantly among patients for whom IONM had been used (1 event among 27,687 patients) and those for whom IONM had not been used (19 events among 349,561 patients). Similarly, spinal cord injury was reported for 229 patients; incidence did not differ significantly $(\mathrm{p}=0.203$ ) among patients for whom IONM had been used (22 events among 27,688 pa- 


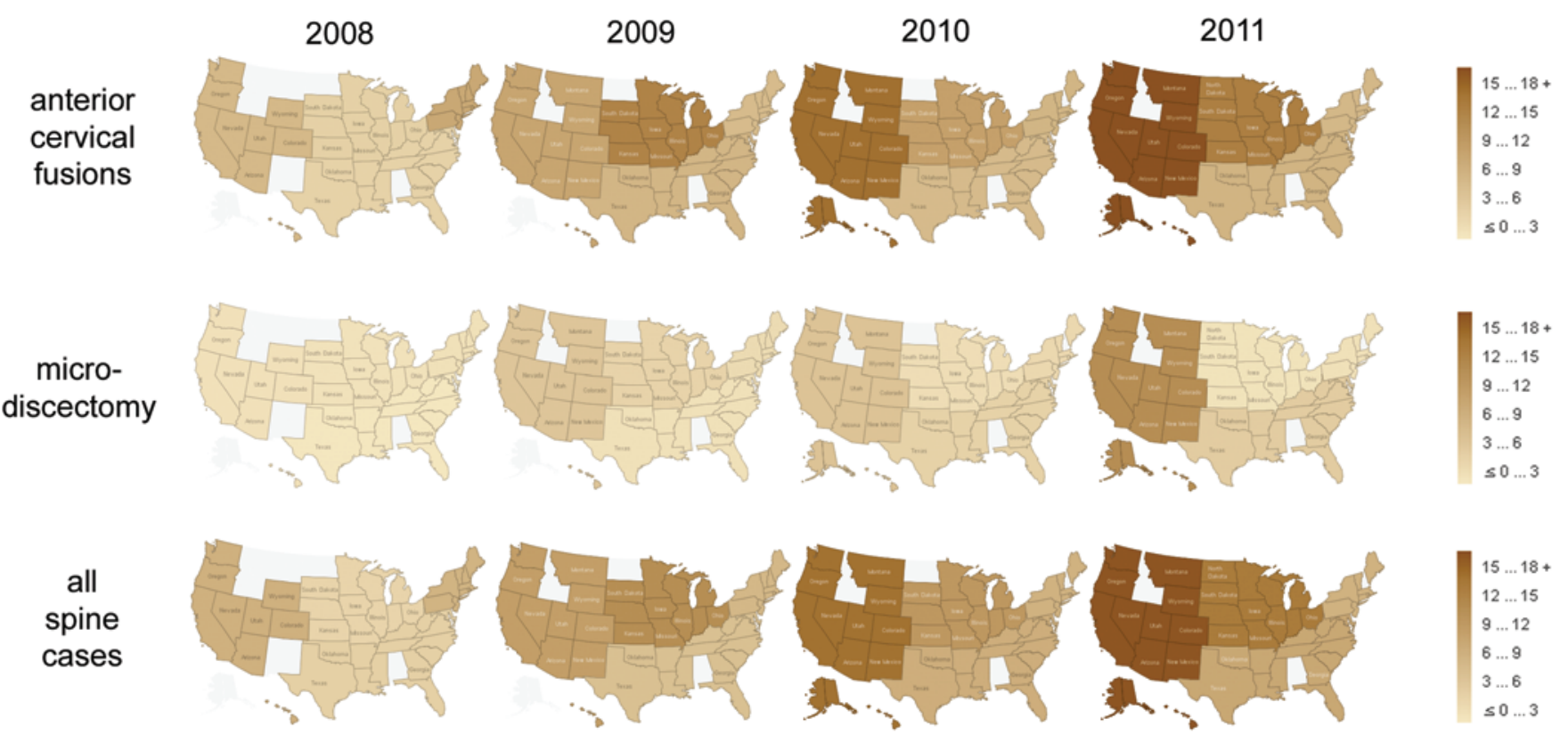

FIG. 1. Illustration showing the increase in percentage use, by geographic region, of IONM during anterior cervical discectomy and fusion surgeries, microdiscectomy surgeries, and all spine surgeries in the United States, 2008-2011.

tients) and those for whom IONM had not been used (207 events among 349,561 patients).

\section{Discussion}

This study illuminates several trends in the use of IONM during spine surgery in the United States. First, use has increased notably in recent years. Second, this increase is associated with marked variation in a hospi- tal's geographic location, relative population density, and teaching status. And third, use increased steadily across all types of spine surgery, even those that have traditionally been viewed as lower-risk surgeries (e.g., anterior cervical discectomy and fusion in the absence of myelopathy, posterior lumbar fusion for lumbago, and lumbar discectomy).

The reasons for increased use of IONM remain unanswerable by this data set. We speculate that the reasons

TABLE 4: Role of IONM regarding patient independence at discharge after common spine procedures and diagnoses

\begin{tabular}{|c|c|c|c|c|c|}
\hline \multirow[b]{2}{*}{ Variable } & \multirow[b]{2}{*}{ No. } & \multicolumn{2}{|c|}{$\begin{array}{l}\text { Percentage of Patients } \\
\text { Discharged to Home }\end{array}$} & \multicolumn{2}{|c|}{ Multivariate Analysis } \\
\hline & & IONM & No IONM & OR & p Value \\
\hline \multicolumn{6}{|l|}{ procedure } \\
\hline laminectomy & 51,981 & 82 & 86 & 0.796 & $<0.0001$ \\
\hline microdiscectomy & 252,472 & 91 & 94 & 0.771 & $<0.0001$ \\
\hline atlantoaxial fusion & 800 & 67 & 73 & 0.741 & 0.062 \\
\hline anterior cervical fusion & 92,603 & 97 & 98 & 0.907 & 0.062 \\
\hline posterior cervical fusion & 6,175 & 76 & 78 & 0.976 & 0.71 \\
\hline anterior thoracic fusion & 1,258 & 68 & 71 & 1.099 & 0.432 \\
\hline posterior thoracic fusion & 5,702 & 60 & 60 & 1.102 & 0.05 \\
\hline anterior lumbar fusion & 30,925 & 86 & 89 & 1.015 & 0.756 \\
\hline $\begin{array}{l}\text { posterior lumbar fusion } \\
\text { diagnosis }\end{array}$ & 135,582 & 84 & 85 & 1.033 & 0.183 \\
\hline disc degeneration & 156,875 & 88 & 90 & 0.946 & 0.029 \\
\hline disc displacement & 194,817 & 94 & 95 & 0.849 & $<0.0001$ \\
\hline fracture & 5,009 & 67 & 68 & 0.828 & $<0.0001$ \\
\hline myelopathy & 29,572 & 89 & 90 & 0.981 & 0.725 \\
\hline scoliosis & 11,591 & 74 & 74 & 1.072 & 0.213 \\
\hline spinal tumor of meninges & 708 & 73 & 74 & 0.456 & $<0.0001$ \\
\hline spinal cord tumor & 526 & 73 & 69 & 1.104 & 0.587 \\
\hline
\end{tabular}


might include the willingness of surgeons to adopt new technology, increasing availability of IONM, medicolegal concerns, and even financial incentive. Although the increased use of IONM during 2007, after introduction of an ICD-9 code for IONM, might reflect, in part, more accurate coding, we suspect that the trend observed over the 4 years is not simply artifactual. The lack of change in use in hospitals in the Northeast over this time frame might even indicate an internal control, displaying a relative regional constant in use of IONM.

To date, there is no established consensus regarding the use of IONM during low-risk spine surgeries. In fact, studies have argued against the use of this monitoring modality during lumbar discectomy. ${ }^{1}$ Use of IONM for lumbar spinal fusion procedures has also been shown to be of no clear benefit; ${ }^{16}$ it can introduce misleading or unreliable intraoperative findings. ${ }^{6}$

Similar to lack of consensus for low-risk lumbar surgeries, there is not yet consensus supporting the use of IONM during low-risk cervical spine surgeries.$^{15}$ Indeed, our study showed no difference in independence at discharge between patients in whom IONM was used versus patients in whom IONM was not used during elective anterior cervical discectomy and fusion surgery. The absence of IONM use during low-risk cervical spine surgery is supported by other studies that have reported a lack of iatrogenic nerve and spinal cord injury among patients who underwent cervical spine surgery without use of IONM. ${ }^{19}$ Other studies suggest that use of IONM during cervical spine surgeries can actually misinform the surgeon and result in inaccurate intraoperative findings. ${ }^{11,18}$ Alternatively, some researchers argue that IONM contributes to prevention of new postoperative neurological deficits in patients undergoing low-risk cervical spine surgeries. Roh et al. reported that somatosensory evoked potential monitoring prompted an intervention for $2.1 \%$ of 809 patients consecutively undergoing cervical spine surgery and probably prevented neurological sequelae in $82 \%$ of patients for whom an intervention was made. ${ }^{17}$ Additionally, Epstein et al. compared morbidity and mortality rates among 218 unmonitored patients and 100 monitored patients who underwent cervical spine surgery and found rates to be $3.7 \%$ and $0.5 \%$, respectively, among unmonitored patients and $0 \%$ among monitored patients, a difference that was attributed to early somatosensory evoked potential detection of spinal cord compromise and immediate corrective action. ${ }^{4}$

Some evidence suggests that IONM prevents postoperative neurological deficits in patients undergoing more complex spinal procedures, particularly deformity correction. ${ }^{13,14}$ Indeed, use of IONM with somatosensory evoked potentials and transcranial motor evoked potentials represents the minimum standard of care for patients undergoing scoliosis surgery. ${ }^{13}$ Additionally, one would expect use of IONM to prevent neurological deficits in patients undergoing spine surgery in which the spinal cord or its nerve roots are intimately involved with the pathology (e.g., spinal cord tumor and spinal dysraphism)..$^{8,10}$ There is evidence to support use of IONM during revision spine surgeries, which inherently pose higher risk for neurological injury.
In an era when iatrogenic nerve and spinal cord injury are rare, the increased use of IONM during spine surgery could be attributed to a developing culture in surgery that is quick to adopt new technologies, ${ }^{9,12}$ thereby increasing medicolegal concerns among spine surgeons, ${ }^{4}$ or it could be attributed simply to artifact (increased application of the ICD-9 code for IONM after its introduction in 2007). The variation seen in association with geographic region, urban versus rural settings, and status as a teaching hospital strongly endorses the notion that there is a tangible trend toward increased use, particularly in western states, urban centers, and nonteaching institutions. This increase goes hand-in-hand with the possibility that the increased use of IONM might be a reflection of medicolegal pressures or financial interests. ${ }^{3,13}$

The limitations of the NIS should be briefly discussed. This data set is an administrative data set that fails to capture the true clinical variables at play. Data abstraction is prone to errors. Incorporation of a new ICD-9 code might lead to some lag in its full utilization. The true economic implications are also very difficult to assess by using this data set alone. Although hospital charges are captured, hospital costs are not, and the relationship between these can be rather opaque.

Despite these limitations, our findings display a clear lack of consensus on the value of this technique; data to support its use in low-risk spine surgeries are equivocal at best. Thus, the trend of increased use of IONM, particularly during low-risk spine surgeries, might warrant further exploration with large prospective trials. In the absence of higher-quality data to drive guidelines, we recommend limiting use of IONM to procedures with a theoretically greater likelihood of intraoperative cord or nerve injury, such as cases of severe spinal cord compression or deformity correction, and abstaining from its use during simpler surgeries, such as anterior cervical fusion without myelopathy and lumbar microdiscectomy.

\section{Conclusions}

Use of IONM during spine surgery has increased dramatically in recent years; use varies markedly according to hospital region, relative population density, and teaching status. In this data set, use of IONM did not strongly correlate with improved patient independence at discharge or prevention of iatrogenic nerve or spinal cord injury. The trend of increased use of IONM in general, and during low-risk spine surgeries in particular, may warrant further exploration, given a lack of consensus to support its use in such cases. We recommend limiting use of IONM to procedures with a theoretically greater likelihood of intraoperative value (e.g., severe spinal cord compression or deformity correction) and abstaining from its use for simpler surgeries (e.g., anterior cervical fusion without myelopathy and lumbar microdiscectomy).

\section{Acknowledgments}

We thank the neurophysiologists at the University of Arizona Medical Center for their input, ideas, and advice as this project was underway. They are stellar examples of individuals who work on a daily basis to improve the quality of patient care. 


\section{Increased use of intraoperative monitoring during spine surgery}

\section{Disclosure}

The authors report no conflict of interest concerning the materials or methods used in this study or the findings specified in this paper.

Author contributions to the study and manuscript preparation include the following. Conception and design: all authors. Acquisition of data: Dumont. Analysis and interpretation of data: Sheen James, Dumont. Drafting the article: all authors. Critically revising the article: all authors. Reviewed submitted version of manuscript: all authors. Approved the final version of the manuscript on behalf of all authors: Sheen James. Statistical analysis: Dumont. Administrative/technical/material support: Dumont. Study supervision: Dumont.

\section{References}

1. Dimopoulos VG, Feltes CH, Fountas KN, Kapsalakis IZ, Vogel RL, Fuhrmann B, et al: Does intraoperative electromyographic monitoring in lumbar microdiscectomy correlate with postoperative pain? South Med J 97:724-728, 2004

2. Elixhauser A, Steiner C, Harris DR, Coffey RM: Comorbidity measures for use with administrative data. Med Care 36:827, 1998

3. Epstein NE: The need to add motor evoked potential monitoring to somatosensory and electromyographic monitoring in cervical spine surgery. Surg Neurol Int 4 (Suppl 5):S383-S391, 2013

4. Epstein NE, Danto J, Nardi D: Evaluation of intraoperative somatosensory-evoked potential monitoring during 100 cervical operations. Spine (Phila Pa 1976) 18:737-747, 1993

5. Gonzalez AA, Jeyanandarajan D, Hansen C, Zada G, Hsieh PC: Intraoperative neurophysiological monitoring during spine surgery: a review. Neurosurg Focus 27(4):E6, 2009

6. Gundanna M, Eskenazi M, Bendo J, Spivak J, Moskovich R: Somatosensory evoked potential monitoring of lumbar pedicle screw placement for in situ posterior spinal fusion. Spine J 3:370-376, 2003

7. Hamilton DK, Smith JS, Sansur CA, Glassman SD, Ames CP, Berven SH, et al: Rates of new neurological deficit associated with spine surgery based on 108,419 procedures: a report of the scoliosis research society morbidity and mortality committee. Spine (Phila Pa 1976) 36:1218-1228, 2011

8. Hoving EW, Haitsma E, Oude Ophuis CM, Journée HL: The value of intraoperative neurophysiological monitoring in tethered cord surgery. Childs Nerv Syst 27:1445-1452, 2011

9. Hrabalek L, Adamus M, Gryga A, Wanek T, Tucek P: A comparison of complication rate between anterior and lateral approaches to the lumbar spine. Biomed Pap Med Fac Univ Palacky Olomouc Czech Repub 158:127-132, 2014

10. Hsu W, Bettegowda C, Jallo GI: Intramedullary spinal cord tumor surgery: can we do it without intraoperative neurophysiological monitoring? Childs Nerv Syst 26:241-245, 2010
11. Khan MH, Smith PN, Balzer JR, Crammond D, Welch WC, Gerszten P, et al: Intraoperative somatosensory evoked potential monitoring during cervical spine corpectomy surgery: experience with 508 cases. Spine (Phila Pa 1976) 31:E105E113, 2006

12. Kinney GA, Slimp JC: Intraoperative neurophysiological monitoring technology: recent advances and evolving uses. Expert Rev Med Devices 4:33-41, 2007

13. Lall RR, Lall RR, Hauptman JS, Munoz C, Cybulski GR, Koski T, et al: Intraoperative neurophysiological monitoring in spine surgery: indications, efficacy, and role of the preoperative checklist. Neurosurg Focus 33(5):E10, 2012

14. Nuwer MR, Dawson EG, Carlson LG, Kanim LE, Sherman JE: Somatosensory evoked potential spinal cord monitoring reduces neurologic deficits after scoliosis surgery: results of a large multicenter survey. Electroencephalogr Clin Neurophysiol 96:6-11, 1995

15. Resnick DK, Anderson PA, Kaiser MG, Groff MW, Heary RF, Holly LT, et al: Electrophysiological monitoring during surgery for cervical degenerative myelopathy and radiculopathy. J Neurosurg Spine 11:245-252, 2009

16. Resnick DK, Choudhri TF, Dailey AT, Groff MW, Khoo L, Matz PG, et al: Guidelines for the performance of fusion procedures for degenerative disease of the lumbar spine. Part 15: electrophysiological monitoring and lumbar fusion. J Neurosurg Spine 2:725-732, 2005

17. Roh MS, Wilson-Holden TJ, Padberg AM, Park JB, Riew KD: The utility of somatosensory evoked potential monitoring during cervical spine surgery: how often does it prompt intervention and affect outcome? Asian Spine J 1:43-47, 2007

18. Smith PN, Balzer JR, Khan MH, Davis RA, Crammond D, Welch WC, et al: Intraoperative somatosensory evoked potential monitoring during anterior cervical discectomy and fusion in nonmyelopathic patients - a review of 1,039 cases. Spine J 7:83-87, 2007

19. Traynelis VC, Abode-Iyamah KO, Leick KM, Bender SM, Greenlee JD: Cervical decompression and reconstruction without intraoperative neurophysiological monitoring. Clinical article. J Neurosurg Spine 16:107-113, 2012

Manuscript submitted July 15, 2014

Accepted August 19, 2014.

Portions of this work were presented at the 82nd American Association of Neurological Surgeons Annual Scientific Meeting, San Francisco, California, April 5-9, 2014.

Please include this information when citing this paper: DOI: 10.3171/2014.8.FOCUS14449.

Address correspondence to: Whitney Sheen James, M.D., M.H.S., University of Arizona, 1501 N. Campbell Ave., P.O. Box 245070, Tucson, AZ 85724-5070. email: whitney.sheen.james@ gmail.com. 